\title{
A Positive Psychology Perspective on Stimulating Foreign Language Learning Motivation
}

\author{
Liyuan Teng \\ College of Foreign Studies, Guilin University of Technology, Guilin 541004, China
}

\begin{abstract}
Motivation is the most direct factor affecting learning initiative. Previous studies on learning motivation have paid enough emphasis on how to reduce the negative effects of demotivation factors, while positive internal and external factors influencing learning motivation have not been drawn sufficient attention. Positive psychology is a psychological trend of studying positive aspects such as human strength and virtue, and advocates taking the perspective of "whole person" to focus the learning achievements and individual well-being of foreign learners. Based on positive psychology, this paper discusses how to stimulate foreign language learning motivation from the aspects of positive emotional experience, positive individual traits and positive institutions, which provides new ideas and implications for the related study on language teaching.
\end{abstract}

Keywords: Motivation, English as a Foreign Language (EFL), Positive psychology.

\section{Introduction}

Motivation is one of important affective factors influencing foreign language learning. In recent years, the research focus on foreign language motivation has been turned to demotivation because it plays vital role in determining the quality of foreign language education. The variables leading to foreign language demotivation can be classified as two categories: internal and external dimensions. The internal factors mainly include students' self-distrust, anxiety and tension. lack of self-confidence. The external factors are examination system, teaching environment, the role of teachers and so on. Therefore, how to effectively adjust internal and external factors, balance positive and negative variables for creating new conditions to remotivate students in foreign language learning has drawn extensive concern of foreign educators and researchers.

With the emergence of Positive Psychology (PP) in second language acquisition (SLA), a newly developing teaching concept that focuses on human advantages and helps them succeed and complete self-realization has been paid growing attention, which broadens language researcher's view of the perception on the goals of foreign language education-foreign language learning can also be an approach to promote human well-being. As a result, PP provides broader and more positive perspective for the study of foreign language motivation. From the view of PP, stimulating foreign language learning motivation refers to paying more attention to learners' positive subjective experience and positive individual characteristics, exploring their unique advantages in positive emotional experience and making full use of these advantages to face the difficulties or negative experiences in the learning process while finding positive value from it, and turning it into positive experience, which forms a virtuous emotional circle ultimately maintaining foreign language learning motivation.

\section{The Significance of Positive Psychology in Foreign Language Learning Motivation}

What is the meaning of learning a foreign language for individuals? From the perspective of PP, the goals of foreign language education are not only for improving learner's language knowledge, skills even the teaching efficiency, but also for caring about the mental health of teaching and learning, which in turn fosters learner's well-being (Li 2021). The self-determination theory of motivation research divides human motivation into intrinsic motivation and extrinsic motivation. Intrinsic motivation means a person engages in certain behavior for achieving happiness and satisfaction; extrinsic motivation refers to a person engages in an act in order to obtain a certain result. The emphasis on intrinsic motivation is voluntary while extrinsic motivation emphasizes being forced. If learners can gain positive emotions such as happiness and satisfaction in foreign language learning, their internal motivations can naturally be effectively stimulated, resulting in a voluntary learning of a foreign language from within rather than under external pressure. Then the problem of foreign language demotivation is solved from another angle.

The focus of PP is on the positive traits of being happy, satisfied and self-fulfilled rather than the abnormal and illness mentalities in previous psychological studies (Seligman and Csikszentmihalyi, 2000). Seligman (2011) proposed that the well-being theory composed of five dimensions which forms the PERMA model: positive emotion, engagement, meaning, positive relationships, and accomplishment. Based on this model, the happiness of language teachers and students is discussed more specifically from Oxford's (2016) EMPATHICS model which contains key elements like emotion and empathy; meaning and motivation; perseverance; agency and autonomy; time; hardiness and habits of mind; intelligence; character strengths; self-factors. From both two models, we can draw an implication that learning a foreign language is closely related to one's happiness which displays other perspective of motivating learners by certain affective factors in foreign language teaching.

Littlewood (1984) proposes that learner's engagement and their perseverance for foreign language learning depends on their motivation. According to a definition provided by Gardner (1985) foreign language motivation refers to an individual works or strives to learn the language because of a desire to do so and the satisfaction experienced in this activity. Those factors affected foreign language motivation just belongs to the three pillars of positive psychology in the field of SLA. They are positive experiences (e.g., enjoyment, 
interest, flow, etc.), positive individual traits (e.g., courage, perseverance, intelligence, tolerance, emotional intelligence, love, etc.), positive institutions (e.g., classroom environment, etc.). Therefore, more innovative and practical insights can be applied to motivate foreign language learners from above three dimensions of positive psychology.

\section{Strategies of Stimulating Foreign Language Learning Motivation from the Perspective of Positive Psychology}

\subsection{Cultivating Leaners' Emotional Intelligence to Improve Foreign Language Leaning Interest and Enjoyment}

The road of foreign language learning is full of difficulties and challenges, learners will inevitably produce all kinds of negative emotional experiences, and even the phenomenon of demotivation. From the perspective of PP, positive emotions have the effect of offsetting or reducing negative emotions (Fredrickson 2001), and promote students' resilience and perseverance to overcome language difficulties and encourage learners to explore and play (Dewaele et al., 2018), which are crucial for stimulating and maintaining foreign language motivation. Closely related to the above emotions, emotional intelligence (EI) refers to an individual's ability to realize, perceive, evaluate, understand, and regulate the emotions of himself and others (Mayer \& Salovey 1997). According to empirical research (Dewaele et al. 2008, Li 2020), EI and enjoyment were significantly positively correlated while the remarkable negative correlation was found between EI and anxiety, indicating that students with higher levels of EI were more likely to experience enjoyment and lower levels of anxiety during the process of English learning. In other words, the more emotionally capable learners are, the less likely they are to burn out in learning English, and the easier it is to maintain motivation to learn.

Positive psychology proposed an ARGUER model and Three activities designed mainly in with emotional experiences in English as Foreign Language (EFL) learning contexts, which have been proved as efficient interventions not only to bolster EI but also to boost foreign language enjoyment (FLE) and reduce foreign language anxiety (FLA). The acronym ARGUER represents six dimensions namely "Awareness, Recognition, Generation, Utilization, Expressing, and Regulation", which are interrelated emotional skills. In the model, students' awareness of feelings and emotion in EFL contexts can be aroused and highlighted by recognizing emotion in self and others through verbal and non-verbal clues (e.g., facial expression, spatial movement, volume, pitch, pause, repetition, gesture, posture). They are able to generate positive emotions after understanding causes and consequences of emotion in class as well as realizing the importance of emotions in both language learning and wellbeing. As a result, students are expected to express their emotion appropriately in different ways and regulate emotions in self and then to share them with their peers or teachers. The more importantly, they can learn the most effective way to deal with negative emotions especially in English learning, which are very helpful for maintaining their learning motivation. The other PP-based intervention "Three Activities" refers to "identifying three good things, savoring positive experiences, and developing learned optimism" in English learning (MacIntyre et al., 2012,). The more positive emotions can be promoted, the more negative emotions can be reduced and managed due to the joint effects of gains in different EI dimensions and positive emotions. Those interventions both emphasized the important role of the ability to recognize emotions in communication and in interactions in English class. As learner's EI has been improved, their happiness, optimism, emotional regulation and self-motivation can help them overcome difficulties as well as gain and keep momentum in foreign language learning.

\subsection{Developing Teachers' Positive Individual Traits to Enhance Students' Willingness to Communicate}

Different from other subjects, language learning is the process of interaction between teachers and students, consequently teacher factors have become the main cause that affect the motivation of foreign language learning. Among them, the teacher's ontological features (personality characteristics, professional quality, external image), personal attitude (teaching attitude, life attitude), feedback type (positive feedback, negative feedback) have an important impact on students' willingness to communicate and motivation to learn second language (Lin et al., 2018). In particular, teachers who were humorous, friendly, patient, supportive, respectful of students were appreciated by their students. Since good teachers character is conducive to closer teacher-student relationship and gives students sufficient language and emotional support, students have a relatively safe classroom experience, which can make them actively participate in classroom activities.

The positive individual traits of teachers are one of the three core concerns in PP theory. According to the theoretical framework of PERMA in PP, MacIntyre (2019) found that the teacher's emotional stability was most correlated with each dimensions of PERMA (positive, engagement, sense, positive relationships, and accomplishments), which were positively correlated, especially with positive emotions, but negatively correlated with negative emotions. The scores of well-being in PERMA were significantly associated with the personality traits, such as likeability, responsibility, emotional stability and intelligence. In other words, the more positive the emotional experience teachers have, the stronger the happiness of teaching. In this case, teachers are more likeable, responsible, emotional stable and intelligent, and vice versa. Teachers who are full of positive emotions are capable of creating group dynamics, likeability, mutual trust, and positive atmosphere that encourages students to focus more on learning and enhance their awareness of language input and output, thereby better absorbing and internalizing foreign languages. Therefore, developing teachers' positive individual traits is beneficial to improve students' willingness to communicate, thereby motivating students in foreign language learning. From a psychological point of view, mindfulness training can be used to improve positive individual traits such as empathy, compassion, life satisfaction, and caring for others (Emerson et.al., 2017) In addition, working memory capacity training helps to improve emotion regulation and reduce negative emotional experiences 
(Schmeichel et.al., 2010), thus better accumulating positive emotions and developing positive individual traits.

\subsection{Creating Positive Classroom Environment from Multiple Dimensions}

Positive psychology holds that the classroom environment has a significant predictive effect on enjoyment and anxiety, the positive foreign language classroom environment is more communicative, in which students are also more likely to enjoy foreign language learning, away from anxiety. Therefore, teacher ought to make great effort to create positive classroom environment from multiple dimensions.

From the cognitive point of view, teachers should strive to design and organize classroom activities meet the students' current cognitive level and their foreign language proficiency, and select interesting teaching materials to cater students' needs to enhance the interestingness of foreign language learning, and produce positive value and attraction for classroom teaching, because the control-value theory in PP considers the positive value of activities or learning content and controllability help learners enjoy their academic program (Pekrun, 2006). The innovative, interesting and challenging classroom activities that are consistent with students' abilities usually enhances their willingness to communicate (Zarrinabadi, 2014), thus increasing their motivation and enjoyment of participating in the classroom.

From the perspective of environmental factors, teachers should create a relaxed, open and inclusive classroom atmosphere, so that students have more autonomy and voice, because they are the main body of information processing, as well as the active builder of cognitive structure, rather than passive recipients stimulated and instilled by external world. In order to create a positive and enjoyable learning environment in the classroom, teachers should focus on the spatial layout of the classroom, and the circular seats can increase the learner's access to the teacher, thereby enhancing the sense of trust, compassion, and belonging in the language learner community (Murphey et.al., 2014).

From the emotional level, teachers should not only pay attention to students' cognitive needs, but also care for their emotional needs, to see their efforts in foreign language learning, and timely give them affirmation and encouragement. Students usually want feedback from teachers on the classroom performance they strive to demonstrate, and effective evaluation by teachers gives them a sense of enjoyment. Teacher's support for students is reflected not only in verbal affirmation and encouragement to them, but also in non-verbal behavior of emotional support. The friendly behavior of teachers such as smiling and patting on the shoulder can shorten the distance between teachers and students, make students feel love and support, and improve their enthusiasm for classroom participation (Fallah 2014).

\section{Conclusion}

Foreign language education is a very complex process involving both negative and positive factors. From the perspective of positive psychology, the study of foreign language learning motivation does not only focus on the influence of negative emotions such as anxiety on learning motivation, but also pays more attention to the positive factors of teachers and students to promote motivation. The research of Positive Psychology has made us realize that the goal of foreign language education is no longer limited to helping learners acquire language knowledge and skills but should also promote the well-being of learners and teachers. This provides new ideas for the foreign language learning motivation, which makes foreign language educators pay more attention to the positive emotions of teachers and students, positive individual traits and positive multidimensional teaching environment. In short, it is not easy to stimulate and enhance students' motivation for foreign language learning, and foreign language educators need to study the internal and external factors affecting motivation more comprehensively and dynamically, so that students can learn to use their own advantages and positive experiences to deal with difficulties while facing up to negative emotions such as anxiety, self-distrust, tension, so as to maintain their enthusiasm and motivation for foreign language learning.

\section{References}

[1] Dewaele J M, Petrides K V, Furnham A. Effects of Trait Emotional Intelligence and Sociobiographical Variables on Communicative Anxiety and Foreign Language Anxiety Among Adult Multilinguals: A Review and Empirical Investigation [J]. Language Learning, 2008, 58(4): 911-960.

[2] Dewaele, J-M., J. Witney, K. Saito \& Dewaele, L. Foreign Language Enjoyment and Anxiety in the FL Classroom: The Effect of Teacher and Learner Variables[J]. Language Teaching Research, 2018, 22: 676-697.

[3] Emerson, L.M., Leyland, A., Hudson, K., et al. Teaching Mindfulness to Teachers: a Systematic Review and Narrative Synthesis [J]. Mindfulness, 2017, 8(5): 11361149.

[4] Fallah, N. Willingness to Communicate in English, Communication Self-confidence, Motivation, Shyness and Teacher Immediacy among Iranian English-major Undergraduates: A Structural Equation Modeling Approach [J]. Learning and Individual Differences, 2014, (30): 140-147.

[5] Fredrickson, B. L. The Role of Positive Emotions in Positive Psychology: The Broaden-and-build Theory of Positive Emotion[J]. American Psychologist, 2001(3): 218-226.

[6] Gardner, R.C. Social Psychology and Second Language Learning: The Role of Attitudes and Motivation[M]. E. Arnold, 1985.

[7] Li, C. A Positive Psychology Perspective on the Research of Second Language Acquisition: Review and Prospect (2012-2021) [J]. Foreign Language Education, 2021, 42(04):57-63.

[8] Li, C. Exploring the Relationship between Emotional Intelligence and English Academic Achievement-Comediating Effect of Enjoyment, Anxiety and Burnout [J]. Foreign Language World, 2020(01): 69-78.

[9] Lin, D., Wang, J., Research on Teacher Factors Influencing Students' Classroom Willingness to Communicate $[\mathrm{J}]$. Foreign Language Education, 2018, 39(04): 59-64. 
[10] Littlewood W. Foreign and Second Language Learning[M]. Cambridge University Press, London: Edward Arnold, 1985.

[11] MacIntyre, P. D., Gregersen, T., S. Mercer. Setting an Agenda for Positive Psychology in SLA: Theory, Practice, and Research[J]. Modern Language Journal, 2019(1): 262-274.

[12] MacIntyre, P. D., \& Gregersen, T. (2012). Emotions that Facilitate Language Learning: The Positive-broadening Power of the Imagination. Studies in Second Language Learning and Teaching, 2(2): 193-213.

[13] Mayer, J. D. \& Salovey, P. What is Emotional Intelligence? [A]. In Salovey P \& Sluyter D (Eds.). Emotional Development and Emotional Intelligence: Educational Implications [C]. New York: Basic Books, 1997.

[14] Murphey, T., Falout, J., et al. Socio-dynamic Motivating through Idealizing Classmates[J]. System, 2014(45): 242-253

[15] Oxford R L. Powerfully Positive: Searching for a Model of Language Learner Well-being [J]. Positive Psychology Perspectives on Foreign Language Learning and Teaching, 2016.

[16] Pekrun, R. The Control-value Theory of Achievement Emotions: Assumptions, Corollaries, and Implications for Educational Research and Practice[J]. Educational Psychology Review, 2006(4): 315-341.

[17] Schmeichel, B. J., Demaree, H. A. Working Memory Capacity and Spontaneous Emotion Regulation: High Capacity Predicts Self-enhancement in Response to Negative Feedback [J]. Emotion, 2010, 10(5): 739-744.

[18] Seligman, M. E. P. \& M. Csikszentmihalyi. Positive Psychology: An Introduction[J]. American Psychologist, 2000(1): 5-14.

[19] Seligman, M. E. P. Flourish: A Visionary New Understanding of Happiness and Well-Being[M]. New York: Free Press, 2011.

[20] Zarrinabadi, N. Communicating in a Second Language: Investigating the Effect of Teacher on Learners' Willingness to Communicate [J]. System, 2014(42): 288-295. 